\title{
Total synthesis of leopolic acid A, a natural 2,3-pyrrolidine- dione with antimicrobial activity
}

\author{
Atul A. Dhavan ${ }^{1}$, Rahul D. Kaduskar ${ }^{1}$, Loana Musso ${ }^{1}$, Leonardo Scaglioni ${ }^{1}$, \\ Piera Anna Martino ${ }^{2}$ and Sabrina Dallavalle ${ }^{*}, \S$
}

\section{Full Research Paper}

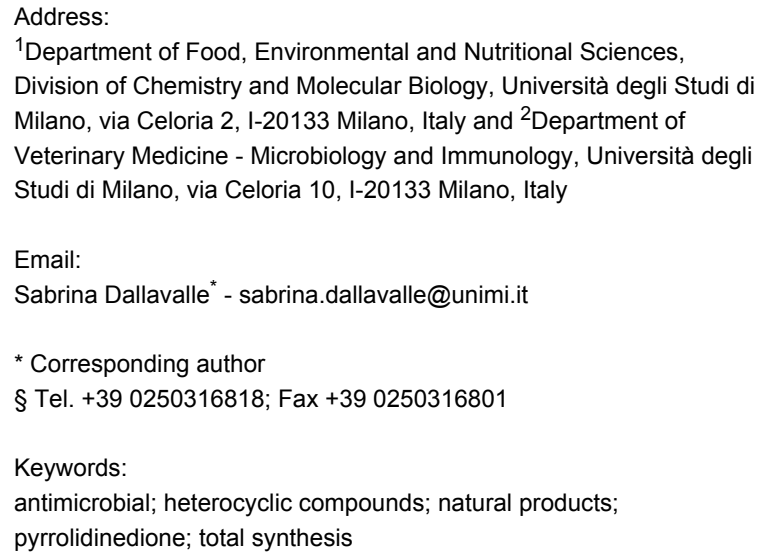

Beilstein J. Org. Chem. 2016, 12, 1624-1628. doi:10.3762/bjoc. 12.159

Received: 01 June 2016

Accepted: 14 July 2016

Published: 29 July 2016

Associate Editor: J. S. Dickschat

(C) 2016 Dhavan et al.; licensee Beilstein-Institut. License and terms: see end of document.

\begin{abstract}
The first total synthesis of leopolic acid A, a fungal metabolite with a rare 2,3-pyrrolidinedione nucleus linked to an ureido dipeptide, was designed and carried out. Crucial steps for the strategy include a Dieckmann cyclization to obtain the 2,3-pyrrolidinedione ring and a Wittig olefination to install the polymethylene chain. An oxazolidinone-containing leopolic acid A analogue was also synthesized. The antibacterial activity showed by both compounds suggests that they could be considered as promising candidates for future developments.
\end{abstract}

\section{Introduction}

Great concern has recently been expressed about the diminishing efficacy of current antibiotic therapies and the emergence of multidrug resistant strains. Novel potent compounds endowed with new mechanisms of action are urgently needed. In this regard, natural products continue to be a rich source of biologically validated structures, which can be modified and optimized in drug discovery [1].

Chemical analysis of a terrestrial-derived Streptomyces sp. isolated from the rhizosphere of the plant Juniperus excelsa yielded a new metabolite, leopolic acid A (1, Figure 1) [2]. Leopolic acid has unprecedented structural features consisting of an aliphatic side chain attached to a 2,3-pyrrolidinedione residue, which in turn, is connected to the ureido dipeptide L-Phe-L-Val. The compound showed antifungal and antibacterial activity against Mucor hiemalis and Staphylococcus aureus with a MIC of 32 and $16 \mu \mathrm{g} / \mathrm{mL}$, respectively [2].

Compounds containing the isomeric 2,4-pyrrolidinedione ring system (tetramic acids) are widespread among the fungal 
<smiles>CC1=C(O)C(=O)N(C(=O)C(NC(=O)N[C@@H](Cc2ccccc2)C(=O)O)C(C)C)C1</smiles>

leopolic acid $\mathrm{A}$

Figure 1: Structure of leopolic acid A.

metabolites and show a number of biological activities, i.e., antibacterial, antiviral, antifungal and anticancer. More than one hundred of them have been isolated from a variety of natural sources [3].

Conversely, natural compounds with a simple 2,3-pyrrrolidinedione nucleus are indeed very few [4-6]. Even though this core can be considered an attractive target, synthetic studies directed to find new biologically active compounds are scarce as well [7-9].
The unique structure and bioactivity of leopolic acid prompted us to plan a synthesis which might be used in the preparation of various analogues. A retrosynthetic disconnection of $\mathbf{1}$ at the amide bond gave two fragments, the ureido dipeptide L-Phe-LVal and 4-decyl-3-hydroxy-1,5-dihydropyrrol-2-one, which appeared well suited for a convergent synthetic approach (Figure 1).

\section{Results and Discussion}

A straightforward route to the intriguing 2,3-pyrrolidinedione system appeared to be the Michael addition of a suitable amine to ethyl acrylate, followed by a Dieckmann cyclization with diethyl oxalate $[10,11]$. We chose the $p$-methoxybenzyl (PMB) protecting group for the amine, because of its facile cleavage with cerium ammonium nitrate (CAN) or 2,3-dichloro-5,6dicyanobenzoquinone (DDQ). Thus, 2,3-pyrrolidinedione 3 was obtained by the reaction of ethyl acrylate with $p$-methoxybenzylamine, followed by treatment with diethyl oxalate (Scheme 1) [12]. On the basis of NMR data, the compound exists as an enol tautomer (see Supporting Information File 1).<smiles>C=CC(=O)OCC</smiles><smiles>CCOC(=O)C1=C(O)C(=O)NC1</smiles>

7 4 PMB 5 6 PMB<smiles>CCOC(=O)C1=C(OCc2ccccc2)C(=O)N(C(=O)C(NC(=O)OC(C)(C)C)C(C)C)C1</smiles>
8 9<smiles>[Y]C(C)C=CC1=C(OCc2ccccc2)C(=O)N(C(=O)C(NC(C)C)C(C)C)C1</smiles>

10

11<smiles>CC1=C(O)C(=O)N(C(=O)C(NC(=O)N[C@@H](Cc2ccccc2)C(=O)O)C(C)C)C1</smiles>

1

Scheme 1: Synthesis of leopolic acid A. Reagents and conditions: a) p-methoxybenzylamine, EtOH, rt, $12 \mathrm{~h}, 98 \%$; b) diethyl oxalate, NaOEt, EtOH, reflux, $3 \mathrm{~h}, 83 \%$; c) $\mathrm{BnBr}, \mathrm{K}_{2} \mathrm{CO}_{3}$, DMF, $0{ }^{\circ} \mathrm{C}$ to rt, $1 \mathrm{~h}, 50 \%$; d) DIBAL-H, $\left.\mathrm{CH}_{2} \mathrm{Cl}_{2},-78{ }^{\circ} \mathrm{C}, 2 \mathrm{~h}, 56 \% ; \mathrm{e}\right) \mathrm{PPh}_{3}, \mathrm{CBr}_{4}, \mathrm{CH}_{2} \mathrm{Cl}_{2}, \mathrm{rt}, 5 \mathrm{~h}, 52 \%$; f) $\mathrm{PPh}$, toluene, reflux, $5 \mathrm{~h}, 75 \%$; g) $n$-nonanal, LiHMDS, THF, $-78{ }^{\circ} \mathrm{C}$ to rt, $5 \mathrm{~h}, 52 \%$; h) CAN, $\mathrm{CH}_{3} \mathrm{CN}: \mathrm{H}_{2} \mathrm{O}, 0{ }^{\circ} \mathrm{C}$ to rt, $3 \mathrm{~h}, 73 \%$; i) 2 -tert-butoxycarbonylamino-3-methylbutyric acid pentafluorophenyl ester, $n$-BuLi, THF, $-78{ }^{\circ} \mathrm{C}, 0.5 \mathrm{~h}, 71 \%$; j) DIBAL-H, $\mathrm{CH}_{2} \mathrm{Cl}_{2},-78{ }^{\circ} \mathrm{C}, 2 \mathrm{~h}, 30 \%$; $\mathrm{k}$ ) PCC, $\mathrm{CH}_{2} \mathrm{Cl}_{2}, 0{ }^{\circ} \mathrm{C}$ to rt, $12 \mathrm{~h}, 46 \%$; I) $n$-nonyltriphenylphosphonium bromide, $n$-BuLi, THF, $-78{ }^{\circ} \mathrm{C}$ to $0{ }^{\circ} \mathrm{C}, 2 \mathrm{~h} ; \mathrm{m}$ ) TFA, $\mathrm{CH}_{2} \mathrm{Cl}_{2}, 0{ }^{\circ} \mathrm{C}$ to rt, $1 \mathrm{~h}$; $\mathrm{n}$ ) L-phenylalanine benzyl ester DIEA, triphosgene, $\mathrm{CH}_{2} \mathrm{Cl}_{2}$, rt, $1 \mathrm{~h}, 60 \%$ over three steps; o) $\mathrm{H}_{2}$, Pd/C, EtOAc, rt, $2 \mathrm{~h}, 77 \%$. 
Indeed, perusal of the literature indicated that apparently all 4-monosubstituted 2,3-pyrrolidinediones are highly enolized [13-15]. Protection of the enolic $\mathrm{OH}$ with a benzyl group, using $\mathrm{BnBr}$ and $\mathrm{K}_{2} \mathrm{CO}_{3}$, gave compound 4 . The reduction of 4 with DIBAL-H gave the corresponding primary alcohol, which was converted into bromide 5 by Appel reaction with $\mathrm{PPh}_{3}$ and $\mathrm{CBr}_{4}$. The phosphonium salt obtained from this bromide was subjected to a Wittig reaction with nonanal, to afford compound 6 [12].

Attempts to remove the PMB protecting group (CAN, DDQ, TFA or hydrogenation) from 6 or from the intermediate alcohol and bromide resulted in the decomposition of the products. The instability of these and other derivatives of the N-unsubstituted ring, already observed by others [11], made the synthetic task more troublesome than expected.

The NH-free pyrrolidinedione scaffold was found to be stable only in the presence of the ester group in position 4. In fact, a deprotected compound 7 could only be obtained by treatment of 4 with CAN.

This result prompted us to install the amino acid fragment on compound 7 before constructing the chain in position 4 , so that it could also act as a NH-protecting group in the following steps. However, as the ureido fragment would interfere with the reduction of the ester group on the nucleus, we opted for installing sequentially the valine, then the phenylalanine residue.

Thus, compound 7 was coupled with pentafluorophenyl esteractivated $N$-Boc-valine to obtain compound 8 (Scheme 1). Treatment with DIBAL-H led to the reduction of both the ester and the $\mathrm{CO}$ group of the valine moiety (9). Compound 9 was obtained as a 9:1 mixture of diastereomers, the syn $(S, S)$ diastereomer being the major one. The selectivity of the reduction is in agreement with previous results and is consistent with the Cram model for a chelation controlled reduction [16-18]. Both $\mathrm{OH}$ groups of compound 9 were oxidized by PCC to obtain aldehyde 10. The long carbon chain was incorporated into $\mathbf{1 0}$ by Wittig olefination with $n$-nonyltriphenylphosphonium bromide and $n$-BuLi at $-78{ }^{\circ} \mathrm{C}(\mathbf{1 1})$. Deprotection and treatment with triphosgene and phenylalanine benzyl ester at rt allowed the formation of compound 13. Finally, catalytic hydrogenation afforded the desired leopolic acid A (1), whose spectroscopic data completely matched with those reported in the literature [1] (see Supporting Information File 2 for NMR spectra).

Interestingly, while searching the best conditions to obtain compound 10, we treated 9 with oxalyl chloride and DMSO, following the Swern protocol [19]. This treatment led to the for- mation of the oxazolidinone $\mathbf{1 4}$ (Scheme 2). We assume that the reaction occurred via inversion of the configuration at the hydroxylated carbon, based on an intramolecular $\mathrm{S}_{\mathrm{N}} 2$ cyclocarbamation by the Boc group [20,21]. The small coupling constant $(J=2.6 \mathrm{~Hz})$ between the two hydrogens on the oxazolidinone ring confirmed that the compound was the anti derivative $[16,17,22,23]$.

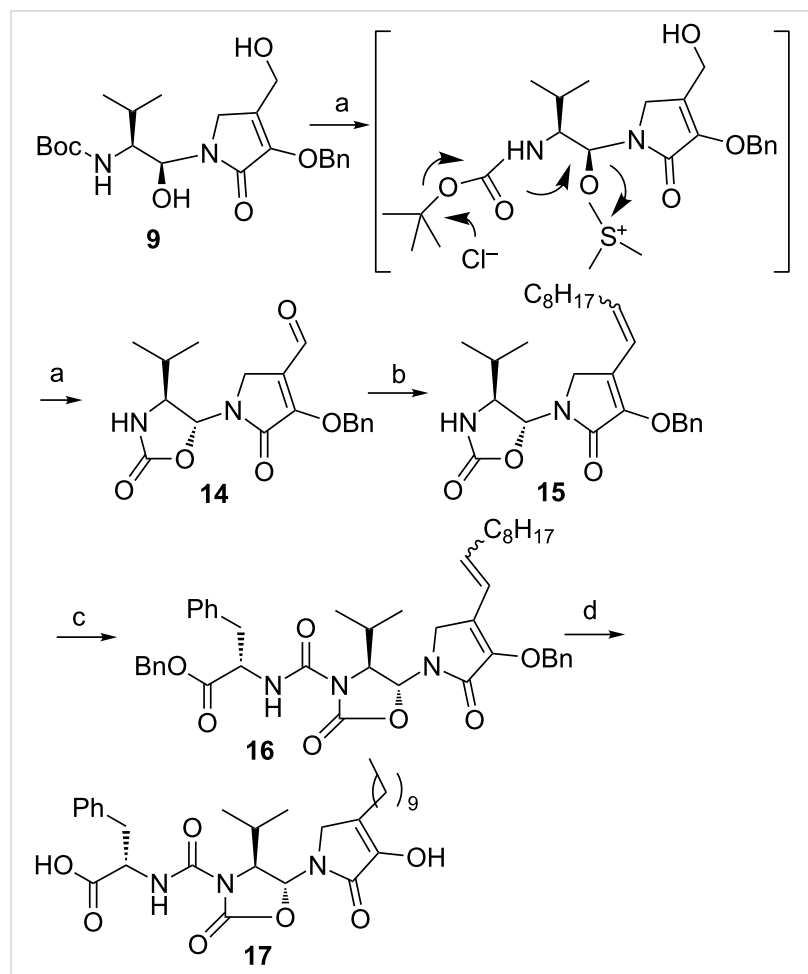

Scheme 2: Synthesis of compound 17. Reagents and conditions: a) Oxalyl chloride, DMSO, $\mathrm{CH}_{2} \mathrm{Cl}_{2}, \mathrm{TEA},-78^{\circ} \mathrm{C}$ to $0{ }^{\circ} \mathrm{C}, 2 \mathrm{~h}, 60 \%$; b) $n$-nonyltriphenylphosphonium bromide, $n$-BuLi, THF, $-78^{\circ} \mathrm{C}$ to $0{ }^{\circ} \mathrm{C}$, $2 \mathrm{~h}, 74 \%$; c) L-phenylalanine benzyl ester, DIEA, triphosgene, $\mathrm{CH}_{2} \mathrm{Cl}_{2}$, rt, 72 h, $49 \%$; d) $\mathrm{H}_{2}$, Pd/C, EtOAc, rt, 2 h, $50 \%$.

The oxazolidinone ring is rare among natural products, but there are successful examples in medicinal chemistry of drugs containing this skeleton, such as the antibiotic linezolid [24].

As the core structure of compound $\mathbf{1 4}$ represents a new scaffold, never isolated or synthesized before, we decided to incorporate the structural features found in leopolic acid into this novel heterocyclic system. Accordingly, Wittig olefination of 14, followed by coupling with L-phenylalanine benzyl ester, and subsequent catalytic hydrogenation in EtOAc of $\mathbf{1 6}$ afforded the analogue of leopolic acid $\mathbf{1 7}$ in $50 \%$ yield.

Compounds 1 and 17 were subjected to a preliminary study of the antimicrobial activity against Staphylococcus and Escherichia coli (Staphylococcus pseudintermedius [25], 25 strains; Escherichia coli, 20 strains. QC: S. aureus ATCC 
25923 and Escherichia coli ATCC 25922 were also used, see Supporting Information File 1 for details). The MIC values of $\mathbf{1}$ against Staphylococcus pseudintermedius range at $16 \mu \mathrm{g} / \mathrm{mL}$, while the values for $\mathbf{1 7}$ against Staphylococcus pseudintermedius are more variable and range between 32 and $64 \mu \mathrm{g} / \mathrm{mL}$. The MIC of $\mathbf{1}$ and $\mathbf{1 7}$ against Escherichia coli range at $128 \mu \mathrm{g} / \mathrm{mL}$ for both molecules (see Supporting Information File 2 for details). The antibacterial activity shown by both compounds suggests that they can be considered as promising candidates for further developments.

\section{Conclusion}

In conclusion, leopolic acid A was obtained for the first time in a 11-step synthesis. The main difficulty encountered was the instability of a number of intermediates containing the 2,3pyrrolidinedione moiety, which may be a reason for the scarce presence of similar compounds in the literature. With these results, we have attained a deeper knowledge of the chemistry of the unusual 2,3-pyrrolidinedione system and developed a synthetic strategy towards new lead compounds with antimicrobial activity. Efforts to synthesize analogues to build a structure-activity relationship (SAR) profile and optimize the activity are underway.

\section{Supporting Information}

\section{Supporting Information File 1}

General experimental methods, synthetic procedures and analytical data for the reported compounds; antimicrobial activity evaluation procedures.

[http://www.beilstein-journals.org/bjoc/content/ supplementary/1860-5397-12-159-S1.pdf]

\section{Supporting Information File 2}

${ }^{1} \mathrm{H}$ and ${ }^{13} \mathrm{C}$ NMR spectra of all the new compounds; 2D HMBC, HSQC spectra of compounds 1, and 17, COSY spectrum of compound 1, MIC of compounds $\mathbf{1}$ and $\mathbf{1 7}$ against Staphylococcus pseudintermedius and Escherichia coli strains.

[http://www.beilstein-journals.org/bjoc/content/ supplementary/1860-5397-12-159-S2.pdf]

\section{Acknowledgments}

The authors gratefully acknowledge Professor L. Merlini for helpful suggestions and discussion.

\section{References}

1. Brown, D. G.; Lister, T.; May-Dracka, T. L. Bioorg. Med. Chem. Lett. 2014, 24, 413-418. doi:10.1016/j.bmcl.2013.12.059
2. Raju, R.; Gromyko, O.; Fedorenko, V.; Luzhetskyy, A.; Müller, R. Tetrahedron Lett. 2012, 53, 6300-6301. doi:10.1016/j.tetlet.2012.09.046

3. Mo, X.; Li, Q.; Ju, J. RSC Adv. 2014, 4, 50566-50593. doi:10.1039/C4RA09047K

4. Tabussum, A.; Riaz, N.; Saleem, M.; Ashraf, M.; Ahmad, M.; Alam, U.; Jabeen, B.; Malik, A.; Jabbar, A. Phytochem. Lett. 2013, 6, 614-619. doi:10.1016/j.phytol.2013.08.005

5. Zuther, K.; Mayser, P.; Hettwer, U.; Wu, W.; Spiteller, P.; Kindler, B. L.; Karlovsky, P.; Basse, C. W.; Schirawski, J. Mol. Microbiol. 2008, 68, 152-172. doi:10.1111/j.1365-2958.2008.06144.x

6. El-Desouky, S. K.; Kim, K. H.; Ryu, S. Y.; Eweas, A. F.; Gamal-Eldeen, A. M.; Kim, Y.-K. Arch. Pharmacal Res. 2007, 30, 927-931. doi:10.1007/BF02993958

7. Pace, P.; Spieser, S. A. H.; Summa, V. Bioorg. Med. Chem. Lett. 2008, 18, 3865-3869. doi:10.1016/j.bmcl.2008.06.056

8. Kawasuji, T.; Fuji, M.; Yoshinaga, T.; Sato, A.; Fujiwara, T.; Kiyama, R. Bioorg. Med. Chem. 2007, 15, 5487-5494. doi:10.1016/j.bmc.2007.05.052

9. Zhu, H.-L.; Ling, J.-B.; Xu, P.-F. J. Org. Chem. 2012, 77, 7737-7743. doi:10.1021/jo301192d

10. Sundberg, R. J.; Pearce, B. C.; Laurino, J. P. J. Heterocycl. Chem. 1986, 23, 537-539. doi:10.1002/jhet.5570230245

11. Coumar, M. S.; Wu, J.-S.; Leou, J.-S.; Tan, U.-K.; Chang, C.-Y.; Chang, T.-Y.; Lin, W.-H.; Hsu, J. T.-A.; Chao, Y.-S.; Wu, S.-Y.; Hsieh, H.-P. Bioorg. Med. Chem. Lett. 2008, 18, 1623-1627. doi:10.1016/j.bmcl.2008.01.068

12. Dhavan, A. A.; Ionescu, A. C.; Kaduskar, R. D.; Brambilla, E.; Dallavalle, S. Bioorg. Med. Chem. Lett. 2016, 26, 1376-1380. doi:10.1016/j.bmcl.2016.01.082

13. Meyer, W. L.; Vaughan, W. R. J. Org. Chem. 1957, 22, 1554-1560. doi:10.1021/jo01363a005

14. Vaughan, W. R.; Covey, I. S. J. Am. Chem. Soc. 1958, 80, 2197-2201. doi:10.1021/ja01542a041

15. Southwick, P. L.; Barnas, E. F. J. Org. Chem. 1962, 27, 98-106. doi:10.1021/jo01048a026

16. Wang, M.; Chen, Y.; Lou, L.; Tang, W.; Wang, X.; Shen, J. Tetrahedron Lett. 2005, 46, 5309-5312. doi:10.1016/j.tetlet.2005.06.050

17. Anzai, M.; Yanada, R.; Fujii, N.; Ohno, H.; Ibuka, T.; Takemoto, Y. Tetrahedron 2002, 58, 5231-5239. doi:10.1016/S0040-4020(02)00499-4

18. Benedetti, F.; Berti, F.; Garau, G.; Martinuzzi, I.; Norbedo, S. Eur. J. Org. Chem. 2003, 1973-1982. doi:10.1002/ejoc.200200626

19. Kaduskar, R. D.; Dhavan, A. A.; Dallavalle, S.; Scaglioni, L.; Musso, L. Tetrahedron 2016, 72, 2034-2041. doi:10.1016/j.tet.2016.03.009

20. Kano, S.; Yokomatsu, T.; Iwasawa, H.; Shibuya, S. Tetrahedron Lett. 1987, 28, 6331-6334. doi:10.1016/S0040-4039(01)91366-8

21. Madhusudhan, G.; Reddy, G. O.; Ramanatham, J.; Dubey, P. K. Tetrahedron Lett. 2003, 44, 6323-6325. doi:10.1016/S0040-4039(03)01508-9

22. Preciado, A.; Williams, P. G. J. Org. Chem. 2008, 73, 9228-9234. doi:10.1021/j08012429

23. Rengasamy, R.; Curtis-Long, M. J.; Seo, W. D.; Jeong, S. H.; Jeong, I.-Y.; Park, K. H. J. Org. Chem. 2008, 73, 2898-2901. doi:10.1021/jo702480y

24. Barbachyn, M. R.; Ford, C. W. Angew. Chem., Int. Ed. 2003, 42, 2010-2023. doi:10.1002/anie.200200528 
25. Devriese, L. A.; Vancanneyt, M.; Baele, M.; Vaneechoutte, M.;

De Graef, E.; Snauwaert, C.; Cleenwerck, I.; Dawyndt, P.; Swings, J.;

Decostere, A.; Haesebrouck, F. Int. J. Syst. Evol. Microbiol. 2005, 55

1569-1573. doi:10.1099/ijs.0.63413-0

\section{License and Terms}

This is an Open Access article under the terms of the Creative Commons Attribution License

(http://creativecommons.org/licenses/by/2.0), which permits unrestricted use, distribution, and reproduction in any medium, provided the original work is properly cited.

The license is subject to the Beilstein Journal of Organic Chemistry terms and conditions:

(http://www.beilstein-journals.org/bjoc)

The definitive version of this article is the electronic one which can be found at:

doi:10.3762/bjoc. 12.159 